\title{
Urinary tract infections and resolution of renal pelvic dilatation in infants
}

\author{
*Sajida Abdulla ${ }^{1}$, Peter Vazhayil ${ }^{1}$, Hariprasad Pallippurath Gopalakrishna Pillai ${ }^{1}$, Manjula Pallippurath \\ Gopalakrishna Divakaran ${ }^{1}$
}

Sri Lanka Journal of Child Health, 2021; 50(1): 69-74

\begin{abstract}
Introduction: Spontaneous resolution is the most common outcome of postnatal renal pelvic dilatation (RPD). Factors which delay spontaneous resolution are poorly studied.
\end{abstract}

Objectives: To study whether urinary tract infection (UTI) delays spontaneous resolution of RPD and to study the outcomes of postnatally detected RPD at one year of age.

Design: Prospective one year study in a tertiary care hospital in Kerala, India.

Method: All inborn babies detected to have at least grade 1 Society for Fetal Urology (SFU) scale of RPD, between postnatal days 3-5, were followed up until resolution or till one year of age. The subjects were divided into mild group (SFU grades 1 and 2) and moderate to severe group (SFU grades 3 and 4). The outcomes assessed were resolution, UTI and need for surgery.

Results: A total of 50 cases were followed up. The mean age of resolution in the mild group was 13 weeks whereas in the moderate to severe group, it was 30.3 weeks. UTI occurred in $9(18 \%)$ patients. Resolution, in those with UTI, occurred at a mean age of 25.7 weeks compared to 14 weeks in those without UTI $(p=0.01)$. Four cases with anteroposterior renal pelvic diameter (APRPD) $>10 \mathrm{~mm}$ with cortical thinning and recurrent UTI resulted in persistent RPD requiring pyeloplasty within one year of life. All preterms showed resolution $(p=0.006)$. Bilateral RPDs showed significantly delayed resolution $(\mathrm{p}=0.002)$.

${ }^{1}$ Government Medical College Ernakuam, Kerala,
India
${ }^{* C o r r e s p o n d e n c e: ~ s a j i a b d u l l a @ g m a i l . c o m ~}$

https://orcid.org/0000-0002-2124-0797

(Received on 29 February 2020; Accepted after revision on 24 April 2020)

The authors declare that there are no conflicts of interest

Personal funding was used for the project.

Open Access Article published under the Creative

Commons Attribution CC-BY (c) (i)

License
Conclusions: UTIs significantly delay resolution of RPD. Mild RPD resolves within 3 months and moderate RPD resolve around 7.5 months of age. Bilateral RPDs significantly delay spontaneous resolution. Preterm RPDs almost always resolve within one year of life.

DOI: http://dx.doi.org/10.4038/sljch.v50i1.9405

(Key words: postnatal outcome, renal pelvic dilatation, resolution, urinary tract infections)

\section{Introduction}

Renal pelvic dilatation (RPD), as determined by prenatal and neonatal ultrasound examination, has a population prevalence of about $2.5 \%$, which decreases to $0.07-0.1 \%$ by the age of 2 years ${ }^{1}$. It has a wide spectrum ranging from a mild dilatation of the renal pelvis alone (pyelectasis), to massive hydronephrosis with renal parenchymal thinning. Spontaneous resolution of RPD occurs more commonly with lower grades of dilatation whereas there is only a $2.6 \%$ chance of spontaneous resolution in those with renal parenchymal thinning ${ }^{2}$. It would be reassuring for the parents and the treating physicians if the time of resolution could be predicted by prospective studies. More importantly, we need to detect RPD which are likely to deteriorate and find out the factors which delay resolution. Children with RPD in fetal anomaly scan and postnatally had 7 times higher risk of hospital admissions related to urinary causes in the first three years of life ${ }^{3}$.

Most of the studies evaluating the outcomes of RPD are retrospective in nature and fail to bring out the actual natural history ${ }^{4-9}$. Resolution rates in previous studies vary from $26 \%$ to $92 \%{ }^{10,11}$. The rationale for conducting this study is that neither the time of resolution, nor the effect of urinary tract infection (UTI) on RPD could be specified or predicted from these retrospective studies. UTI rates from pooled data ranges from 2.8 to $3.6 \%$ in low grade hydronephrosis and varies from $14.6 \%$ to $28.9 \%$ in those with high grade hydronephrosis ${ }^{12}$. Factors which delay spontaneous resolution are also poorly studied. Other outcomes like need for surgery in the first year of life, in those detected with RPD, are also not clear. 


\section{Objectives}

To study whether UTI delays the resolution of RPD and to study the outcomes of postnatally detected RPD at one year of age.

\section{Method}

A prospective one year observational study was conducted from July 2018 to July 2019 in a tertiary care referral hospital in Kerala, India. All inborn babies with a history of antenatal hydronephrosis, during the study period, were screened for RPD on postnatal day 5 and were included in our study if they had at least grade 1 renal sinus status as per Society for Fetal Urology (SFU) grading system $^{13,14}$. Most of the referred antenatal mothers lacked details of renal sinus in their antenatal scans but their newborns were also included if they were found to have at least grade 1 SFU staging in their first postnatal scan done for any other reason on days 3-5. All babies who had no splitting of renal sinus in their postnatal scans were excluded.

Minimum sample size estimated was 45 , in accordance with a similar study previously done by Asl AS, et $a l^{15}$. Data such as sex, gestational age, birth weight, anteroposterior renal pelvic diameter (APRPD) in $\mathrm{mm}$ in the last third trimester scan and presence or absence of oligohydramnios in the last scan, were documented. Antenatal factors studied were presence of oligohydramnios, gestational diabetes, and pregnancy induced hypertension. All postnatal follow up ultrasounds were done using the same machine, (GE logiq P5, GE, US Technology, Korea) by the same sonologist throughout the study period.

Data recorded from each postnatal scan included: SFU grade, renal length, APRPD of each renal pelvis, calyceal dilatation, renal parenchymal thickness, ureteral dilatation and bladder wall thickness, if present. Based on the last postnatal scan, patients were divided as "mild group" which comprised SFU grades 1 and 2, and "moderate to severe group" which comprised those with SFU grades 3 and 4. First postnatal scan was scheduled between postnatal day 3 and postnatal day 5. This was because ultrasound performed before 3 days will lead to underestimation of severity of hydronephrosis due to the relative dehydration and decreased glomerular filtration rate that are present immediately after delivery ${ }^{16}$. Second postnatal scan was scheduled at 6 weeks. Subsequent follow up scans were scheduled at $12^{\text {th }}, 24^{\text {th }}$ and $52^{\text {nd }}$ weeks ${ }^{17}$. Patients with two normal ultrasounds were not followed up further ${ }^{18}$. Growth assessment and clean catch urinalysis and urine midstream cultures were done at each follow-up visit. Also, suprapubic urine cultures were tested during any febrile episode. Antibiotic prophylaxis with cefadroxil at
$5 \mathrm{mg} / \mathrm{kg} /$ day was given in only those above $10 \mathrm{~mm}$ APRPD $^{19}$. Micturating cystourethrogram (MCU) was done at 6 weeks in those with APRPD $>10 \mathrm{~mm}$, worsening hydronephrosis, UTI or if abnormalities of ureter(s), urethra or bladder were present. In case of suspicion of posterior urethral valves (PUV), MCU was done as soon as possible. ${ }^{99 \mathrm{~m}} \mathrm{Tc}-$ diethylenetriaminepentaacetic acid (DTPA) was done at 6-8 weeks only if there was worsening hydronephrosis and/or in those with RPD $>10 \mathrm{~mm}^{20}$. Blood urea and serum creatinine values were assessed once on postnatal day 5 and repeated if baby developed UTI.

The outcome measures were defined as follows:

1. Resolution: This was considered to occur when the APRPD was $<5 \mathrm{~mm}$ on two consecutive sonograms done at least 4 weeks apart and was the endpoint of follow up. A diagnosis of transient hydronephrosis was made in all cases of resolution.

2. Urinary tract infection: This was diagnosed in the presence of significantly positive urine culture of $10^{5} / \mathrm{mL}$ or more colony-forming units of a single organism per $\mathrm{ml}$ of midstream clean catch sample. In situations when midstream sample was difficult to obtain, babies less than 6 months of age, or when contaminants were grown in culture, suprapubic aspirate (SPA) was obtained and any growth in urine obtained by SPA was considered significant.

3. Paediatric surgery referral: This was done if they had an obstructed renogram with differential renal function $<40 \%$ or impaired drainage $(\mathrm{t} 1 / 2>20 \mathrm{~min})$ or bilateral hydronephrosis or in case of dilated ureter ${ }^{20}$.

These newborns were followed up till resolution or surgery or until the end of one year if hydronephrosis persisted. The frequency and time required for resolution of RPD (primary outcome) were analysed in both mild and moderate to severe hydronephrosis groups. Other outcomes like frequency of UTI, progression of RPD and the proportion of those who underwent surgery were also analysed in the 2 groups. $\mathrm{p}<0.05$ was regarded as statistically significant.

Ethical issues: Ethical approval was obtained from the Ethics and Research Committee of the Government Medical College Ernakuam, Kerala, India (ERC No. F/19/2017/2). Written informed consent was obtained from the mothers prior to commencement of the study 
Statistical analysis was done using SPSS version 20 software. Survival analysis was used to analyse data in which the time until the event of interest occurred. The event studied, here, is resolution of RPD. Survival analysis was done to study the mean times for resolution (Time to Event); as each case has different times of resolution which is the event studied. The starting point of the survival curve corresponds to the $1^{\text {st }}$ postnatal scan. The subjects had frequent follow up times during which ultrasounds were done and the earliest age of resolution was recorded in those cases which showed APRPD less than $5 \mathrm{~mm}$. Those cases who had to undergo surgery were 'censored'. Censoring means the total survival time for that subject cannot be accurately calculated ${ }^{21}$. Comparison between those with UTI and those without UTI was done by Log rank test, Breslow and Taron ware tests were used to test the equality of survival distribution.

\section{Results}

A total of 60 newborns were identified to satisfy the inclusion criteria during the study period. Ten patients were lost to follow up. Of the 50 subjects who completed this study, $40(80 \%)$ were boys and $10(20 \%)$ were girls. The baseline characteristics of the study subjects are described in Table 1.

Table 1: Baseline characteristics $(n=50)$

\begin{tabular}{|l|c|c|}
\hline \multicolumn{1}{|c|}{ Baseline characteristic } & Number (\%) & Number (APRPD) \\
\hline Male & $40(80)$ & \\
\hline Female & $10(20)$ & \\
\hline Term & $32(64)$ & \\
\hline Preterm & $18(36)$ & \\
\hline Left sided renal pelvic dilatation (RPD) & $35(69)$ & \\
\hline Bilateral RPD & $09(18)$ & $23(<10 \mathrm{~mm})$ \\
\hline Antenatally detected RPD & $28(53)$ & $05(>10 \mathrm{~mm})$ \\
\hline $\begin{array}{l}\text { Resolution of antenatally detected RPD in immediate postnatal } \\
\text { scan }\end{array}$ & $23(82)$ & $05(>10 \mathrm{~mm})$ \\
\hline $\begin{array}{l}\text { Persistence of antenatally detected RPD in postnatal scan at } 6 \\
\text { weeks }\end{array}$ & $05(18)$ & $0(<10 \mathrm{~mm})$ \\
\hline Low birth weight & $19(38)$ & $05(>10 \mathrm{~mm})$ \\
\hline
\end{tabular}

APRPD: anteroposterior renal pelvic diameter

The earliest antenatally detected RPD was at 18 weeks of gestation. All the $18(100 \%)$ preterms showed resolution compared to $22(68 \%)$ out of 32 term babies. This difference was found to be statistically significant $(\mathrm{p}=0.006)$. There was no statistically significant difference between gender, laterality and resolution. None of the antenatal factors studied, had any significant relation to resolution. The aetiology of RPD were transient or physiological in 37 babies, uretero-pelvic junction obstruction in 12 babies and 1 had posterior urethral valves (PUV). Data from the first postnatal scan showed that 37 (74\%) babies had SFU grades
1 and 2 . Nine (18\%) babies were of SFU grade 3. Grade 4 SFU with cortical thinning was seen in 4 (8\%) cases. SFU grade 3 and 4 cases showed resolution in only 5 out of $13(38.5 \%)$ moderate to severe cases as shown in Table 2.

Surgery was done in the 4 cases with SFU grade 4 . This included pyeloplasty for 3 patients with pelviureteric junction obstruction and valve ablation for a case of posterior urethral valve.

Febrile UTI was observed in $18 \%$ of the total cases. Its frequency and relation to SFU grade is shown in Table 3.

Table 2: Univariate analysis of outcomes with severity of RPD

\begin{tabular}{|c|c|c|c|c|c|}
\hline Outcome & $\begin{array}{l}\text { Mild } \\
\text { n (\%) }\end{array}$ & $\begin{array}{c}\text { Moderate to severe } \\
\text { n (\%) }\end{array}$ & OR & $95 \%$ CI & $P$ value \\
\hline Resolved & $35(94.6)$ & $05(38.5)$ & \multirow[t]{2}{*}{2.4} & \multirow[t]{2}{*}{$1.2-4.9$} & \multirow[t]{2}{*}{0.001} \\
\hline Not resolved & $02(05.4)$ & $08(61.5)$ & & & \\
\hline UTI Present & $05(13.5)$ & $04(30.8)$ & \multirow[t]{2}{*}{0.43} & \multirow[t]{2}{*}{$0.13-1.3$} & \multirow[t]{2}{*}{0.16} \\
\hline No UTI & $32(86.5)$ & $09(69.2)$ & & & \\
\hline Surgery done & $0(0)$ & $04(30.8)$ & \multirow[t]{2}{*}{ N.A } & \multirow[t]{2}{*}{ N.A } & \multirow[t]{2}{*}{0.003} \\
\hline No surgery & $37(100)$ & $09(69.2)$ & & & \\
\hline
\end{tabular}


Table 3: Urinary tract infection in relation to $S F U$ grade

\begin{tabular}{|c|c|l|l|l|l|}
\hline SFU grade & Cases (n/total) & \multicolumn{1}{|c|}{ organism } & UTI freq & \multicolumn{1}{|c|}{ APRPD } & \multicolumn{1}{c|}{ Complications } \\
\hline 1 & $2 / 32$ & E.coli & Once & $8.9 \mathrm{~mm}$ & None \\
\hline 2 & $3 / 5$ & E.coli & Once & $10 \mathrm{~mm}$ & None \\
\hline 3 & $1 / 9$ & Enterococcus, E.coli & multiple & $9 \mathrm{~mm}$ & RTA \\
\hline 4 & $3 / 4$ & Klebsiella, Enterococci & multiple & $>15 \mathrm{~mm}$ & FTT, dehydration \\
\hline
\end{tabular}

Eight out of nine cases of UTI were males. E.coli was the commonest organism isolated. There was no statistically significant relation between UTI and the SFU grade of RPD $(p=0.16)$. Three out of four cases with UTI having SFU grade 4 and 1 case with SFU grade 3, developed multiple episodes of febrile UTI, requiring hospitalisation in each episode within the first 6 months of life despite antibiotic prophylaxis. Frank pyuria was observed twice in a female baby with SFU grade 3 with vesico-ureteric reflux, but with APRPD of only
$9 \mathrm{~mm}$, who also had renal tubular acidosis. Pyeloplasty resulted in relief of UTI in all these cases.

Resolution occurred only at a mean age of 25.71 weeks, in those with urinary tract infections but in those without UTI, resolution occurred at a mean age of 14.15 weeks. This was found to be a statistically significant difference by both Breslow test $(p=0.01)$; and Taron ware tests of significance $(p=0.026)$ as displayed in Table 4 .

Table 4: Survival characteristics of study sample

\begin{tabular}{|c|c|c|c|c|c|}
\hline UTI & Cases (n) & Resolved (n) & $\begin{array}{c}\text { Censored } \\
(\mathbf{n})(\boldsymbol{\%})\end{array}$ & $\begin{array}{c}\text { Mean survival time (resolution- } \\
\text { event) (weeks) }\end{array}$ & $\mathbf{9 5 \%}$ CI \\
\hline With UTI & 09 & 05 & $04(44.1)$ & 25.71 & $12.59-38.83$ \\
\hline No UTI & 41 & 31 & $10(24.4)$ & 14.15 & $8.42-19.886$ \\
\hline
\end{tabular}

In the mild group, the mean time of resolution was 12.98 weeks with a confidence interval of 8.96 to 17.00 weeks. In those with RPD above $10 \mathrm{~mm}$, the mean time for resolution was 30.3 weeks with a confidence interval of 16.33 to 44.26 weeks. Thirty six $(72 \%)$ showed resolution at 6 weeks and 42 $(84 \%)$ resolved by 6 months of age. At 1 year of age, $8(16 \%)$ had persistent renal pelvic dilatation. Resolution in bilateral RPDs were found to be significantly less $(p=0.002)$ at 6 and 12 weeks postnatal scans. Progression of RPD was seen in those with APRPD $>10 \mathrm{~mm}(\mathrm{P}=0.03)$ and $\mathrm{OR}$ of 4.2 .

\section{Discussion}

The key findings of this study are that UTI significantly delays resolution of hydronephrosis in the infant. Resolution, in those with UTI, occurred at a mean age of 25.7 weeks compared to resolution at age of 14 weeks in those without UTI. Nine $(18 \%)$ developed UTI in our study compared to $10 \%$ UTI observed by Wollenberg et al ${ }^{9}$. We found that only $13.5 \%$ of the mild and $30 \%$ of the moderate to severe RPDs developed UTI within one year of life. None of Wollenberg's mild cases developed UTI. However, our finding is similar to the study by Dellagrammaticus where $12.2 \%$ of mild RPD developed UTI ${ }^{22}$. Prospective study by Coelo et al revealed that $18 \%$ of mild RPD had uropathy and $7.8 \%$ had UTI during a medium-term follow-up time ${ }^{23}$. Our study also confirms their findings that even mild RPD babies need surveillance for UTI. RPD in preterms was seen to resolve completely but resolution does not depend on gender, even though RPD is predominant in males.

The majority (72\%) of the newborns with SFU grade 1 showed resolution as early as 6 weeks. As expected, majority of our mild renal pelvic dilatations (SFU grade 1and 2) resolved within one year $(80 \%)$ compared to $52.7 \%$ of mild cases in a study by Lim et $a l^{2}$. Babu et al .reported resolution in 71 out of $116(61.2 \%)$ of children ${ }^{24}$. Our high resolution rate of $80 \%$ may be because SFU grade 1 was accorded to all babies who had a barely split sinus irrespective of APRPD as the status of the calices is key in SFU grading. The size of the renal pelvis is less important and does not need to be measured as per the original SFU grading by Fernbach et $a l^{14}$. The mean resolution time in the mild cases was around 3 months. Our study shows that only $38.5 \%$ of those with APRPD more than $10 \mathrm{~mm}$, resolved within one year. This delayed and slow resolution could be attributed to the increased rates of UTI (30.8\% UTI in APRPD above 10mm). Mami C, et al. reports that more than $90 \%$ of cases of moderate dilatation of the renal pelvis (APRPD $10 \mathrm{~mm}-14.9 \mathrm{~mm}$ ) resolve spontaneously by $12-24$ months. However, their UTI rate in the moderate group was only $3.6 \%{ }^{11}$. It is prudent to keep the moderate RPDs under follow up and screen them for UTI at each febrile episode, and advise sonological screening for progression of RPD in those with SFU grade above 2 and APRPD $\geq 10 \mathrm{~mm}$. As expected, there was a highly significant $(p=0.003)$ association of surgery for the moderate to severe group. An Indian study by Babu 
$\mathrm{R}$, et al. reports that none among the unilateral RPD cases with APRPD $<15 \mathrm{~mm}$ required surgery ${ }^{24}$. However, we report that even if APRPD is $9 \mathrm{~mm}$, if the baby has recurrent UTI, despite antibiotic prophylaxis and its unilaterality, if there is a pelvi-ureteric junction obstruction, surgical relief of obstruction provides relief from recurrent UTI.

One major limitation of our study was the limited sample size of moderate to severe group. This could be the reason why Log Rank test for significance showed a $\mathrm{p}$ value of 0.06 while the Breslow test and Taron ware showed that UTI significantly delays resolution. Another limitation of the study was that all mothers did not have antenatal ultrasound scan details of renal pelvic dilatation based on SFU grading.

\section{Conclusions}

UTIs significantly delay resolution of RPD. Mild RPD resolves within 3 months and moderate RPD resolve around 7.5 months of age. Bilateral RPDs significantly delay spontaneous resolution. Preterm RPDs almost always resolve within one year of life.

\section{References}

1. Skorecki K, Chertow M. Urinary tract obstruction. In: Skorecki K, Chertow M, Marsden A, Taal W, Yu L, editors. Brenner and Rector's The Kidney. $10^{\text {th }}$ ed. Philadelphia; Elsievier Inc; 2016; 867-8.

2. Lim DJ, Park JY, Kim JH, Paick SH, Oh SJ, Choi H. Clinical characteristics and outcome of hydronephrosis detected by prenatal ultrasonography. Journal of Korean Medical Science 2003; 18(6):85962. https://doi.org/10.3346/jkms.2003.18.6.85 9

PMid: 14676444 PMCid: PMC3055129

3. Hurt L, Wright $\mathrm{M}$, Demmler J, VanDerVoort J, Morris S, Brook F, et al. Mild-to-moderate renal pelvis dilatation identified during pregnancy and hospital admissions in childhood: An electronic birth cohort study in Wales, UK. PLoS Medicine 2019; 16(7):e1002859. https://doi.org/10.1371/journal.pmed.1002 859

PMid: 31361739 PMCid: PMC6667131

4. Vandervoort K, Lasky S, Sethna C, Frank $\mathrm{R}$, Vento $\mathrm{S}$, Choi-Rosen $\mathrm{J}$ et al.
Hydronephrosis in infants and children: natural history and risk factors for persistence in children followed by a medical service. Clinical Medicine: Pediatrics 2009; 3:63-70. https://doi.org/10.4137/CMPed.S3584 PMid: 23818796 PMCid: PMC3676294

5. De Kort EH, BambangOetomo S, Zegers $\mathrm{SH}$. The long-term outcome of antenatal hydronephrosis up to 15 millimetres justifies a non-invasive postnatal followup. Acta Paediatrica 2008; 97(6):708-13. https://doi.org/10.1111/j.16512227.2008.0 0749.x

PMid: 18410468

6. Orabi M, Abozaid S, Sallout B, Abu Shaheen A, Heena H, Al Matary A. Outcomes of isolated antenatal hydronephrosis at first year of life. Oman Medical Journal 2018; 33(2):126-32. https://doi.org/10.5001/omj.2018.24 PMid: 29657681 PMCid: PMC5889835

7. Cordero L, Nankervis CA, Oshaughnessy RW, Koff SA, Giannone PJ. Postnatal follow-up of antenatal hydronephrosis: a health-care challenge. Journal of Perinatology 2009; 29(5):382-7. https://doi.org/10.1038/jp.2008.239 PMid: 19194456

8. Sadeghi-Bojd S, Kajbafzadeh AM, Ansari-Moghadam A, RashidiS. Postnatal evaluation and outcome of prenatal hydronephrosis. Iranian Journal of Pediatrics 2016; 26(2): e3667. https://doi.org/10.5812/ijp.3667 PMid: 27307966 PMCid: PMC4906562

9. Wollenberg A, Neuhaus TJ, Willi UV, Wisser J. Outcome of fetal renal pelvic dilatation diagnosed during the third trimester. Ultrasound in Obstetrics and Gynecology 2005; 25(5):483-8. https://doi.org/10.1002/uog.1879 PMid: 15846759

10. Bragagnini $P$, Estors $B$, Delgado R, Rihuete MÁ, Gracia J. Predictive factors of the outcomes of prenatal hydronephrosis. Archivos Espanoles de Urologia 2016; 69(10):680-90.

11. Mami C, Paolata A, Palmara A, Marrone $\mathrm{T}$, Beste LF, Marseglia L, et al. Outcome and management of isolated moderate 
renal pelvic dilatation detected at postnatal screening. Pediatric Nephrology 2009; 24:2005-8.

https://doi.org/10.1007/s00467-009-12293

PMid: 19582482

12. Braga LH, Mijovic H, Farrokhyar F, Pemberton J, DeMaria J, Lorenzo AJ. Antibiotic prophylaxis for urinary tract infections in antenatal hydronephrosis. Pediatrics 2013; 131(1):251-61. https://doi.org/10.1542/peds.2012-1870 PMid: 23248229

13. Nguyen HT, Herndon CDA, Cooper C, Gatti J, Kirsch A, Kokorowski $\mathrm{P}$, et al. The Society for Fetal Urology consensus statement on the evaluation and management of antenatal hydronephrosis. Journal of Pediatric Urology 2010; 6(3):212-31.

https://doi.org/10.1016/j.jpurol.2010.02.20 5

PMid: 20399145

14. Fernbach SK, Maizels M, Conway JJ. Ultrasound grading of hydronephrosis: introduction to the system used by the Society for Fetal Urology. Pediatric Radiology 1993; 23(6):478-80. https://doi.org/10.1007/BF02012459 PMid: 8255658

15. Asl AS, Maleknejad S. Clinical outcome and follow-up of prenatal hydronephrosis. Saudi Journal of Kidney Diseases and Transplantation 2012; 23(3):526-31.

16. Wiener JS, O Hara SM. Optimal timing of initial postnatal ultrasonography in newborns with prenatal hydronephrosis. Journal of Urology 2002; 168(4 Pt 2):1826-9.

https://doi.org/10.1016/S00225347(05)64 423-0

17. Laing FC, Burke VD, Wing VW, Jeffrey RB Jr, Hashimoto B. Postpartum evaluation of fetal hydronephrosis: optimal timing for follow-up sonography. Radiology 1984; 152:423-4. https://doi.org/10.1148/radiology.152.2.65 39930

PMid: 6539930
18. Bagga A, Sinha A, Gulati A. In: Antenatal Hydronephrosis. In: Protocols in Pediatric Nephrology. $1^{\text {st }}$ ed. New Delhi. CBS Publishers; 2012. 22-27.

19. Bagga A, Sinha A, Gulati A. In: Urinary Tract Infections. In: Protocols in Pediatric Nephrology. $1^{\text {st }}$ ed. New Delhi. CBS Publishers; 2012. 148.

20. Sinha A, Bagga A, Krishna A, Bajpai M, Srinivas M, Uppal R, et al. Revised guidelines on management of antenatal hydronephrosis. Indian Pediatrics 2013; 50(2):215-31. https://doi.org/10.1007/s13312-013-00646

PMid: 23474928

21. Rich TJ, Neely G, Paniello CR, Courtney C, Voelker J, Nussenbaum B. A practical guide to understanding Kaplan-Meier Curves. Otolaryngology, Head and Neck Surgery 2010; 143(3):331-6. https://doi.org/10.1016/j.otohns.2010.05.0 07

PMid: 20723767 PMCid: PMC3932959

22. Dellagrammaticas HD, Iacovidou N, Papadimitriou M, Daskalaki A, Papadoyannis M. Mild dilatation of renal pelvis in term neonates with urinary tract infection. Biology of the Neonate 2001; 79:1-4.

https://doi.org/10.1159/000047057

PMid: 11150822

23. Coelho GM, Bouzada MC, Pereira AK, Figueireido BF, Leite MR, Oliviera SR, et al. Outcome of isolated antenatal hydronephrosis: a prospective cohort study. Pediatric Nephrology 2007; 22(10): 1727-34.

https://doi.org/10.1007/s00467-007-05396

PMid: 17653772

24. Babu R, Sai V. Postnatal outcome of fetal hydronephrosis: Implications for prenatal counselling. Indian Journal of Urology 2010; 26(1):60-2.

https://doi.org/10.4103/0970-1591.60446

PMid: 20535287 PMCid: PMC2878440 